\title{
Disparities in Medical Debt Among U.S. Adults with Serious Psychological Distress
}

\author{
Priscilla J. Novak, ${ }^{1, *}$ Mir M. Ali, ${ }^{1}$ and Maria X. Sanmartin ${ }^{2}$
}

\begin{abstract}
Purpose: To examine indebtedness for medical care among racial and ethnic minorities and people with serious psychological distress (SPD) using a nationally representative sample in the United States.

Methods: Using the 2014-2017 Medical Expenditure Panel Survey, we examine medical debt among individuals with SPD. We develop a logistic regression model to estimate the odds of medical debt by SPD status. We stratify the odds of medical debt for those with SPD by insurance type.

Results: The results indicate that after controlling for predisposing, enabling, and physical needs factors, those experiencing SPD have double the odds of having medical debt compared with those without SPD. NonHispanic blacks had higher odds of medical debt compared with non-Hispanic whites. We find that individuals with SPD covered under private health insurance have double the odds of having medical debts; and those who are uninsured have triple the odds of having medical debt compared with their counterparts without SPD.

Conclusion: The findings suggest that odds of medical debt are higher among people with SPD, even when insured. Additional health policy initiatives to address medical debt among those with SPD may be warranted.
\end{abstract}

Keywords: medical debt; disparities; insurance

\section{Introduction}

Before the passage of the Affordable Care Act (ACA) in 2010, one of the benefits suggested by advocates of health insurance expansion was a hypothesized increase in access to care and reduction in medical debt if more Americans had health insurance. ${ }^{1,2}$ Findings post-ACA indicate that health insurance coverage was expanded ${ }^{3-5}$; however, high out-of-pocket costs continue to create barriers to accessing needed health care. ${ }^{6-10}$ Furthermore, the literature on personal bankruptcy filings suggests that medical conditions continue to be a driver of personal bankruptcy filings. ${ }^{11-13}$ Although the relationship between medical bills and bankruptcy has been studied, fewer studies have been conducted on medical debt. Medical debt may constitute a barrier to appropriate care seeking. However, cost- and debt-related barriers to accessing health care are not evenly distributed and several studies suggest that people with serious psychological distress (SPD) have greater difficulty accessing needed health care. $^{14,15}$

Many of the available studies on medical debts assess care seeking and persistent debts among people who have survived cancer, with the preponderance of evidence suggesting that cancer survivorship is associated with persistent financial hardship and medical debts. ${ }^{16-18}$ Additional studies have examined the odds of filing for bankruptcy after debilitating spinal cord injuries, ${ }^{19}$ the relationship between personal debt and suicidal ideation, ${ }^{20}$ and the relationship between medical debt and use of payday loans. ${ }^{21}$ These studies suggest that there are deleterious influences of

\footnotetext{
${ }^{1}$ Department of Health Policy and Management, School of Public Health, University of Maryland at College Park, College Park, Maryland, USA.

${ }^{2}$ Department of Health Professions, Hofstra University, Hempstead, New York, USA.

*Address correspondence to: Priscilla J. Novak, PhD, MPH, Department of Health Policy and Management, School of Public Health, University of Maryland at College Park, 4200 Valley Dr \#2242, College Park, MD 20742, USA, E-mail pnovak1@umd.edu
} 
having medical debts, including postponing needed care because of a desire to not have any more bills that cannot be paid.

Annually, between $3.5 \%$ and $5 \%$ of the U.S. adult population experiences SPD. ${ }^{22}$ Research on services utilization among U.S. adults with SPD suggests that the ACA increased needed mental health service utilization. $^{23,24}$ Furthermore, having health insurance may decrease anxiety among low-income urban women. ${ }^{25}$ The literature suggests that individuals with SPD have higher utilization of physical health care services than those without SPD, ${ }^{14,15,26}$ and this includes higher numbers of emergency department visits ${ }^{27}$ and poorer health outcomes after surgery. ${ }^{28}$ Although health services utilization are necessary for individuals with SPD, it may be that their high levels of utilization and poorer outcomes after interventions drive high spending and medical debts.

SPD has been reported to increase barriers to receiving adequate health care by increasing care coordination challenges. ${ }^{29-33}$ Given the siloed nature of mental and physical health care delivery in the United States, prior studies indicate that people with SPD have to navigate and pay for care across physical and mental health care providers. ${ }^{34,35}$ Although higher expenditures have been documented for people with SPD, ${ }^{36,37}$ little is known about medical debt among this population. The objective of this study is to examine the impact of SPD on medical debt in a nationally representative sample of U.S. adults. ${ }^{6,38}$ We hypothesize that individuals with SPD will be disproportionately represented in the group with medical debt; and that people with SPD would have higher odds of reporting medical debt compared with people without SPD. This topic is of policy significance as one of the main aims of expanding health insurance coverage was to reduce financial hardship associated with utilization of needed health services.

\section{Methods}

\section{Participants and procedures}

We use data from the 2014-2017 Medical Expenditure Panel Survey (MEPS), public use household file. The MEPS is collected and produced by the Agency for Healthcare Research and Quality and contains information on demographics, health insurance coverage, health care use, and health care expenditures among the U.S. civilian noninstitutionalized population. The Agency for Healthcare Research and Quality uses the Chesapeake Institutional Review
Board for review of its human subjects protections. All MEPS respondents provide informed consent and are free to refuse to participate in the survey without fear of retribution. Completion of the survey ranges between $70 \%$ and $80 \%{ }^{39}$ The MEPS uses a complex sampling design and develops survey weights to make the sample representative of the national population. Survey weights were used in all analysis. This research was deemed exempt by the IRBs of our institutions.

\section{Conceptual model and control variables}

The U.S. civilian noninstitutionalized adults aged 18-64 years are the subjects of this study. We combine 20142017 data using the pooling procedure provided by the MEPS. We use the Kessler-6 score in the MEPS to construct a binary indicator for SPD. The Kessler- 6 screener contains six questions such as, "During the past 30 days, about how often did you feel depressed?" 40 and, "During the past 30 days, about how often did you feel hopeless?." The answers use the categories "all of the time," "most of the time," "some of the time," "a little of the time," or "never." 41 The survey then asks, "Taking them altogether, did these feelings occur "More often in the past 30 days than is usual for you," "about the same as usual," or "less often than usual?" Scores can range between 0 and 24 . People scoring 13 or more are classified as having SPD and those scoring 12 or less are classified as not having SPD. ${ }^{26}$ SPD is not itself a diagnosis, but rather serves as an indicator of distress that is serious enough to warrant additional evaluation by a health care professional. ${ }^{42,43}$

\section{Measures and outcomes}

The binary variable medical debt is based on respondents' answers to the question on "having any medical bills that you are unable to pay at all?" People who indicated that there are bills that they are unable to pay are categorized as having medical debt, and those who responded that this was not the case are categorized as not having medical debt.

We use the Andersen model of health services utilization to select covariates in our model. ${ }^{44}$ The selected covariates include the predisposing characteristics of age, gender (male or female), marital status (currently married or not), and race/ethnicity (non-Hispanic white, non-Hispanic black/African American, Hispanic, Asian American, and other races). The enabling characteristics include educational attainment (less than high school, high school, some college, college, 
or advanced degree) income level (poor, near poor, low income, middle income, or high income), region of residence (northeast, south, midwest, or west), insurance type (private insurance, Medicaid, or uninsured). Finally, for the needs characteristics, we use selfreported health status (excellent, very good, good, fair, and poor).

\section{Statistical analysis}

We first develop descriptive statistics and examine the population characteristics of our sample by stratifying by medical debt status. Among those with SPD, we examine the proportions with medical debt over the 4year period that this study covers. Then, we estimate a logistic regression model to estimate the odds of medical debt when an individual has SPD. Finally, we stratify the models by health insurance type (private insurance, Medicaid, or uninsured) to examine how the impact of SPD on the odds of having medical debt varies by individual's health insurance coverage status. We used Stata 14 to conduct all analysis.

\section{Results}

Table 1 presents demographic characteristics of the respondents in our analysis by their medical debt status. Our analytic sample consists of 78,918 (weighted $N=193$ million) adults, out of whom 5531 (weighted $N=11,363,469)$ reported having medical debt. There was a higher proportion of respondents with SPD among those with medical debt $(0.20$ vs. $0.05 ; p<0.000)$. By race and ethnicity, non-Hispanic white and Asian American adults represented a lower proportion of those with medical debts, whereas non-Hispanic blacks, Hispanics, and multiracial individuals had higher proportions of medical debt $(p<0.000$ for all categories). The proportions of medical debt by education status revealed that those with high school education or less had the highest proportion of medical debt and those with college degree (0.09) and advanced degrees (0.02) had the lowest proportion $(p<0.000$ for all categories). Poor (0.22), low-income (0.22), and middle-income (0.34) groups had higher proportion of medical debt compared with the high-income group (0.14). Those who were not married had a higher proportion of medical debt ( $58 \%$ vs. $42 \%$; $p<0.000$ ).

Among individuals with medical debt, 51\% had private insurance (vs. 75\% among those without medical debt), $28 \%$ had public insurance (vs. $14 \%$ among those without medical debt), and $21 \%$ were uninsured (vs. 11\% among those without medical debt). Finally,
Table 1. Demographic Characteristics of U.S. Adults by Medical Debt Status, Combined Medical Expenditure Panel Survey Data, 2014-2017

\begin{tabular}{|c|c|c|}
\hline & Medical debt & No medical debt \\
\hline & $\begin{array}{l}\text { Weighted } \\
\text { proportions } \\
\text { (std. error) }\end{array}$ & $\begin{array}{l}\text { Weighted } \\
\text { proportions } \\
\text { (std. error) }\end{array}$ \\
\hline \multicolumn{3}{|l|}{ SPD } \\
\hline Yes & $0.20(<0.01)^{* * *}$ & $0.05(<0.01)$ \\
\hline No & $0.80(<0.01)^{* * *}$ & $0.95(<0.01)$ \\
\hline \multicolumn{3}{|l|}{ Self-rated physical health } \\
\hline Excellent & $0.14(0.01)^{* * *}$ & $0.28(0.01)$ \\
\hline Very good & $0.23(0.01)^{* * *}$ & $0.36(0.01)$ \\
\hline Good & $0.33(0.02)^{* * *}$ & $0.27(0.01)$ \\
\hline Fair & $0.20(0.01)^{* * *}$ & $0.08(0.01)$ \\
\hline Poor & $0.10(0.03)^{* * *}$ & $0.02(0.01)$ \\
\hline \multicolumn{3}{|l|}{ Age } \\
\hline $18-25$ years & $0.15(0.01)$ & $0.15(<0.01)$ \\
\hline $26-35$ years & $0.21(0.01)$ & $0.22(<0.01)$ \\
\hline $36-45$ years & $0.19(0.01)$ & $0.20(<0.01)$ \\
\hline $46-55$ years & $0.23(0.01)^{*}$ & $0.22(<0.01)$ \\
\hline $56-64$ years & $0.21(0.01)$ & $0.20(<0.01)$ \\
\hline \multicolumn{3}{|l|}{ Race/ethnicity } \\
\hline Non-Hispanic white & $0.54(0.02)^{* * *}$ & $0.61(0.01)$ \\
\hline Non-Hispanic black & $0.20(0.01)^{* * *}$ & $0.12(0.01)$ \\
\hline Hispanic & $0.20(0.01)^{* *}$ & $0.17(0.01)$ \\
\hline Asian & $0.02(<0.01)^{* * *}$ & $0.06(<0.01)$ \\
\hline Non-Hispanic Other & $0.05(0.01)^{* * *}$ & $0.03(0.01)$ \\
\hline \multicolumn{3}{|l|}{ Marital status } \\
\hline Married & $0.42(0.01)^{* * *}$ & $0.53(0.04)$ \\
\hline Not currently married & $0.58(0.03)^{* * *}$ & $0.47(0.01)$ \\
\hline \multicolumn{3}{|l|}{ Education } \\
\hline$<$ High school & $0.20(0.01)^{* * *}$ & $0.12(0.01)$ \\
\hline High school & $0.37(0.01)^{* * *}$ & $0.28(0.01)$ \\
\hline Some college & $0.32(0.01)^{* * *}$ & $0.28(0.01)$ \\
\hline College & $0.09(0.01)^{* * *}$ & $0.20(0.01)$ \\
\hline$>4$ Years of college & $0.02(0.01)^{* * *}$ & $0.12(0.01)$ \\
\hline \multicolumn{3}{|l|}{ Health insurance } \\
\hline Private insurance & $0.51(0.03)^{* * *}$ & $0.75(0.01)$ \\
\hline Public insurance & $0.28(0.01)^{* * *}$ & $0.14(0.01)$ \\
\hline Uninsured & $0.21(0.02)^{* * *}$ & $0.11(0.01)$ \\
\hline \multicolumn{3}{|l|}{ Income } \\
\hline Poor & $0.22(0.01)^{* * *}$ & $0.11(0.01)$ \\
\hline Near poor & $0.08(0.01)^{* * *}$ & $0.03(0.01)$ \\
\hline Low income & $0.22(0.01)^{* * *}$ & $0.11(0.01)$ \\
\hline Middle income & $0.34(0.01)^{* * *}$ & $0.29(0.01)$ \\
\hline High income & $0.14(0.01)^{* * *}$ & $0.46(0.01)$ \\
\hline$N$ & 5531 & 73,387 \\
\hline Weighted $N$ & 13.4 million & 193 million \\
\hline
\end{tabular}

Source: Authors' analysis of data for 2014-2017 from the Medical Expenditure Panel Survey.

$N=78,918$ MEPS respondents, of whom 5531 stated that they had medical debts that they could not pay at all. The proportions are weighted using survey weights to make the results nationally representative. * Significant at $p<0.05$ confidence level.

**Significant at $p<0.005$ confidence level.

***Significant at $p<0.001$ confidence level.

MEPS, Medical Expenditure Panel Survey; SPD, serious psychological distress.

among those with medical debt 14\% reported to be in excellent health and $23 \%$ reported to be in very good health.

From Figure 1, we see that proportion of individuals with SPD had a consistent and higher prevalence of 
medical debt compared with their counterparts without SPD. Specifically, in 2014, $22 \%$ of those with SPD had medical debt compared with $6 \%$ of individuals without SPD. The proportions were constant over the years with $20 \%$ versus $5 \%$ in $2015,20 \%$ versus $5 \%$ in 2016 , and $18 \%$ versus $5 \%$ in 2017 .

Table 2 reports estimates from logistic regression model examining the correlation between SPD and the odds of having medical debt. The results indicate that compared with individuals without SPD, individuals with SPD had higher odds (odds ratio [OR] 1.99; $p<0.000$ ) of medical debt. Poor self-reported physical health was a strong predictor of medical debt (OR 5.44; $p<0.000$ ). No significant correlation was observed across the age categories. Females had slightly higher odds of having medical debt (OR 1.07; $p<0.05$ ). Non-Hispanic blacks (OR 1.24; $p<0.000)$ and other race/ethnicity (OR 1.56; $p<0.000$ ) had higher odds of medical debt, than the non-Hispanic whites. Asian Americans (OR $0.45 ; p<0.000$ ) had lower odds of medical debt compared with non-Hispanic whites.

Across the enabling characteristics, those who had completed college (OR $0.60 ; p<0.000)$ or with more than a 4-year college degree (OR 0.36; $p<0.000)$ had lower odds of medical debt. Compared with individuals $<100 \%$ of the Federal Poverty Level (FPL), those who were near poor (i.e., $101-138 \%$ of the FPL; OR $1.24 ; p<0.05)$ and low income (i.e., $139-200 \%$ of the FPL; OR 1.28; $p<0.000$ ) had higher odds of medical debt. Those with high incomes (i.e., $>400 \%$ of the FPL; OR 0.37; $p<0.000$ ) had lower odds of medical debt. Respondents living in the south (OR 1.38; $p<0.000)$ had higher odds of medical debt, whereas those residing in the west (OR $0.75 ; p<0.001$ ) had lower odds of medical debt, compared with residents of the northeast.

In Table 3, we stratify our logistic regression by health insurance type status. Among those who were uninsured, having SPD was associated with approximately three times the odds of having a medical debt (OR 2.96; $p<0.000$ ). Among those with private insurance, the odds ratio for medical debt among those with SPD was $2.23(p<0.00)$. Finally, for those with Medicaid, the odds ratio for medical debt among those with SPD was $1.56(p<0.00)$.

\section{Discussion}

This study provides preliminary evidence on medical debt among U.S. adults aged 18-64 years, finding that individuals with SPD have double the odds of
Table 2. Odds of Having Medical Debt for Working Aged U.S. Adults, 2014-2017

Odds ratio $p>t \quad 95 \%$ Confidence interval

\begin{tabular}{|c|c|c|c|c|}
\hline \multicolumn{5}{|l|}{ Needs factors } \\
\hline SPD & 1.99 & 0.00 & 1.71 & 2.32 \\
\hline \multicolumn{5}{|c|}{ Self-report of health (excellent is the comparator) } \\
\hline Very good & 1.25 & 0.00 & 1.08 & 1.45 \\
\hline Good & 1.99 & 0.00 & 1.74 & 2.28 \\
\hline Fair & 3.19 & 0.00 & 2.76 & 3.68 \\
\hline Poor & 5.44 & 0.00 & 4.56 & 6.48 \\
\hline \multicolumn{5}{|l|}{ Predisposing factors } \\
\hline \multicolumn{5}{|c|}{ Age (18-29 years is the comparator) } \\
\hline $30-44$ years & 1.00 & 0.96 & 0.88 & 1.14 \\
\hline $45-54$ years & 1.07 & 0.26 & 0.95 & 1.21 \\
\hline $54-65$ years & 0.94 & 0.37 & 0.82 & 1.08 \\
\hline Female & 1.07 & 0.04 & 1.00 & 1.14 \\
\hline Not married & 1.05 & 0.40 & 0.94 & 1.17 \\
\hline \multicolumn{5}{|c|}{ Race/ethnicity (non-Hispanic white is the comparator) } \\
\hline Non-Hispanic black & 1.24 & 0.00 & 1.08 & 1.41 \\
\hline Hispanic & 0.90 & 0.24 & 0.76 & 1.07 \\
\hline Asian American & 0.45 & 0.00 & 0.31 & 0.63 \\
\hline Other race/ethnicity & 1.56 & 0.00 & 1.21 & 2.01 \\
\hline \multirow{2}{*}{\multicolumn{5}{|c|}{$\begin{array}{l}\text { Enabling factors } \\
\text { Education (less than high school is the comparator) }\end{array}$}} \\
\hline & & & & \\
\hline \multicolumn{5}{|c|}{$\begin{array}{llll}\text { High school } & 1.00 & 0.97 & 0.89\end{array}$} \\
\hline Some college & 0.99 & 0.92 & 0.86 & 1.15 \\
\hline College & 0.60 & 0.00 & 0.48 & 0.74 \\
\hline Advanced degree & 0.36 & 0.00 & 0.26 & 0.49 \\
\hline \multicolumn{5}{|c|}{ Insurance (private insurance is the comparator) } \\
\hline Public insurance & 1.05 & 0.48 & 0.92 & 1.21 \\
\hline Uninsured & 1.56 & 0.00 & 1.35 & 1.82 \\
\hline \multicolumn{5}{|c|}{ Income category (poor is the comparator) } \\
\hline Near poor & 1.24 & 0.03 & 1.02 & 1.52 \\
\hline Low income & 1.28 & 0.00 & 1.12 & 1.46 \\
\hline Middle income & 0.95 & 0.49 & 0.82 & 1.10 \\
\hline High income & 0.37 & 0.00 & 0.30 & 0.46 \\
\hline \multicolumn{5}{|c|}{ Region (northeast is the comparator) } \\
\hline Midwest & 1.16 & 0.27 & 0.89 & 1.51 \\
\hline South & 1.38 & 0.00 & 1.11 & 1.70 \\
\hline West & 0.74 & 0.01 & 0.59 & 0.94 \\
\hline \multicolumn{5}{|c|}{ Year (2014 is the comparator) } \\
\hline 2015 & 0.93 & 0.33 & 0.81 & 1.08 \\
\hline 2016 & 0.94 & 0.42 & 0.81 & 1.09 \\
\hline 2017 & 0.80 & 0.01 & 0.68 & 0.95 \\
\hline
\end{tabular}

Bold text indicates statistically significant results.

Source: Authors' analysis of data for 2014-2017 from the Medical Expenditure Panel Survey.

$N=78,297$. Survey weights were used to make the results nationally representative.

Table 3. Odds Ratio of Medical Debt by Health Insurance Status

\begin{tabular}{cccc}
\hline & Uninsured $(\mathrm{Cl})$ & Private insurance $(\mathrm{Cl})$ & Medicaid $(\mathrm{Cl})$ \\
\hline SPD & $2.96^{* * *}(2.11-4.15)$ & - & - \\
- & $2.23^{* * *}(1.72-2.88)$ & - \\
& - & - & $1.56^{* * *}(1.28-1.91)$
\end{tabular}

Source: Authors' analysis of data for 2014-2017 from the Medical Expenditure Panel Survey.

$N=78,297$. Survey weights were used to make the results nationally representative. Control variables include age, gender, marital status, education, income, insurance coverage, self-reported health status, and survey year.

${ }^{* *}$ Significant at $p<0.001$ confidence level.

$\mathrm{Cl}$, confidence interval. 


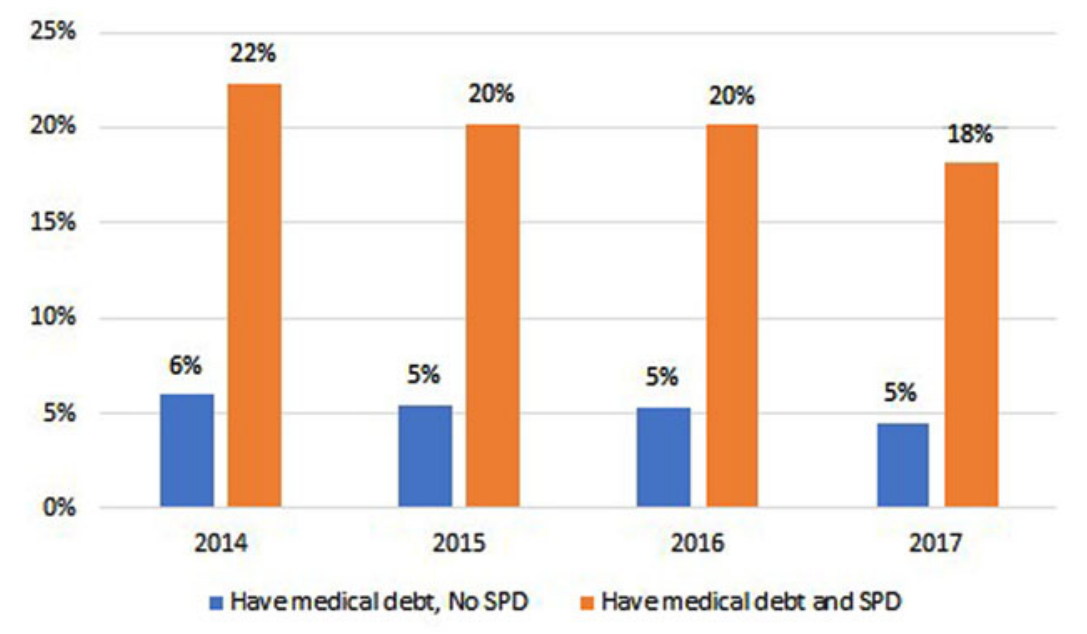

FIG. 1. Medical debt by SPD status among adults aged 18-64 years, 2014-2017. Source: Authors' analysis of data for 2014-2017 from the Medical Expenditure Panel Survey. $N=2908$ people with SPD. The proportions are weighted using survey weights to make the results nationally representative. "Medical debt" refers to respondents who reported that they had bills that they could not pay at all. Differences between those with and without SPD are significant at the $p<0.001$ confidence level across all 4 years. SPD, serious psychological distress.

medical debt, with the strongest relationship among those who are uninsured, followed by private insurance, and then Medicaid. The finding that SPD was associated with increased odds of medical debt among those who were uninsured, as well as among those with private health insurance coverage signifies the risk that SPD possess in terms of medical debt and financial instability.

Our stratified model showed that the odds of having medical debt for those with SPD but covered under Medicaid and private insurance is statistically significant, suggesting that there might be a potential problem with benefit design for both Medicaid and private insurance since it is unable to protect individuals with SPD from incurring medical debt. This finding adds to the literature on barriers to health services utilization among individuals with SPD by providing evidence that they not only have difficulty in accessing care, but also are more likely to incur medical debt. ${ }^{45}$ People with SPD have a high level of need for health care services. Plan design may benefit from additional consideration of what services beneficiaries with SPD utilize that result in them having medical debt. Some health systems have begun offering housing, ${ }^{46}$ employment, ${ }^{47}$ and financial literacy ${ }^{48}$ services in an effort to address the social determinants of health among those with SPD, and additional research on how these programs function may inform best practices in population health management.

\section{Health equity implications}

Race and ethnicity had an important relationship with medical debt, with higher odds of medical debt among non-Hispanic blacks and the multiracial ethnic group and lower odds of medical debt among Asians compared with their non-Hispanic white counterparts. In our model, there was a positive correlation between medical debt and being in a low-income group. We hypothesize that this may be because although Medicaid expansion covered low-income individuals, it was not available to those who were near poor but who marginally exceeded the ceiling for Medicaid coverage. We observed that college completion and advanced degree holders had lower odds of medical debt, signifying the potential mitigating impact of education on medical debt. We also observed geographic differences. Those residing in the south had higher odds of medical debt, whereas those living in the west had lower odds of medical debt. This finding is consistent with the fact that many of the states that chose not to expand Medicaid eligibility were located in the south. 
We borrow from the stress accumulation model of disease to hypothesize that people with medical debts may experience heightened anxiety, which could increase health inequity. Assuming that the SPD was present first and that the need for health services arose second, one might rightly propose additional measures to promote population mental health. However, our study does not capture the direction of the relationship between SPD and medical debt. If medical debt heightens anxiety, feelings of hopelessness, and feeling "down," one might correctly propose to target medical debt as the causal factor to be addressed through health policy and programs. We observed little change in the rates of medical debt across 20142017. Given that the full implementation of the ACA began in 2014, the MEPS only began collecting data on medical debt in 2014. Additional MEPS data years might provide greater insight into temporal trends in medical debt.

There are some limitations that are worth noting. First, our study was observational and the interpretation of a causal relationship between SPD and medical debt must be undertaken with caution. Second, as in all survey-based research, there is the possibility of recall bias or social desirability influencing answers. Finally, we are unable to control for the amount of the medical debt that people have. The Federal Reserve Board has published data briefs indicating that $>30 \%$ of American households have $<\$ 400$ in emergency cash reserves to pay for unexpected expenses. ${ }^{49}$ Thus, we are able to measure the impact of SPD on only the likelihood of incurring a medical debt but not on the amount of medical debt, which might be higher among individuals with SPD compared with their counterparts without SPD.

\section{Conclusion}

This initial study provides preliminary evidence on higher odds of medical debt among U.S. adults with SPD. SPD was associated with statistically significant higher odds of medical debt regardless of the individuals' health insurance status. Policy initiatives to address health insurance coverage and health services utilization might benefit from being cognizant of the financial hardship that SPD imparts on individuals even when they have health insurance. More research is needed to determine effective solutions to enable Americans with SPD to avoid medical debt.

\section{Author Disclosure Statement}

No competing financial interests exist.

\section{Funding Information}

No funding was received to support this study.

\section{References}

1. Seifert RW, Rukavina M. Bankruptcy is the tip of a medical-debt iceberg. Health Aff. 2006;25:w89-w92.

2. Doty MM, Edwards JN, Holmgren AL. Seeing red: Americans driven into debt by medical bills. Results from a National Survey. Issue Brief. 2005: $1-12$.

3. Sommers BD, Gunja MZ, Finegold K, et al. Changes in self-reported insurance coverage, access to care, and health under the Affordable Care Act. JAMA. 2015;314:366-374.

4. Sommers BD, Gawande AA, Baicker K. Health insurance coverage and health-what the recent evidence tells us. N Engl J Med. 2017;377: 586-593.

5. Caswell KJ, Waidmann TA. The Affordable Care Act Medicaid expansions and personal finance. Med Care Res Rev. 2019;76:538-571.

6. Rabin DL, Jetty A, Petterson S, et al. Under the ACA higher deductibles and medical debt cause those most vulnerable to defer needed care. J Health Care Poor Underserved. 2020;31:424-440.

7. McMorrow S, Kenney GM, Long SK, et al. Marketplaces helped drive coverage gains in 2015; affordability problems remained. Health Aff. 2016;35:1810-1815.

8. Chen J, Vargas-Bustamante A, Novak P. Reducing young adults' health care spending through the ACA expansion of dependent coverage. Health Serv Res. 2017:52:1835-1857.

9. Selden TM, Lipton BJ, Decker SL. Medicaid expansion and marketplace eligibility both increased coverage, with trade-offs in access, affordability. Health Aff. 2017;36:2069-2077.

10. Cubanski J, Neuman T, Damico A, et al. Medicare beneficiaries' out-ofpocket health care spending as a share of income now and projections for the future The Henry J. Kaiser Family Foundation. Published 2018. Available at https://www.kff.org/report-section/medicare-beneficiariesout-of-pocket-health-care-spending-as-a-share-of-income-now-andprojections-for-the-future-report/ Accessed January 3, 2019.

11. Dickman SL, Himmelstein DU, Woolhandler S. Inequality and the healthcare system in the USA. Lancet. 2017;389:1431-1441.

12. Himmelstein DU, Woolhandler S, Warren E. Myth and measurement-the case of medical bankruptcies. N Engl J Med. 2018;378:2245-2246.

13. Himmelstein DU, Lawless RM, Thorne D, et al. Medical bankruptcy: still common despite the Affordable Care Act. Am J Public Health. 2019;109: 431-433.

14. Weissman J, Russell D, Jay M, et al. Racial, ethnic, and gender disparities in health care access and use among U.S. adults with serious psychological distress. Psychiatr Serv. 2018;69:517-522.

15. Weissman JD, Russell D, Beasley J, et al. Relationships between adult emotional states and indicators of health care utilization: findings from the National Health Interview Survey 2006-2014. J Psychosom Res. 2016; 91:75-81.

16. Altice CK, Banegas MP, Tucker-Seeley RD, et al. Financial hardships experienced by cancer survivors: a systematic review. J Natl Cancer Inst. 2017;109.

17. Banegas MP, Guy GP, Jr., de Moor JS, et al. For working-age cancer survivors, medical debt and bankruptcy create financial hardships. Health Aff. 2016;35:54-61.

18. Banegas MP, Schneider JL, Firemark AJ, et al. The social and economic toll of cancer survivorship: a complex web of financial sacrifice. J Cancer Surviv. 2019;13:406-417.

19. Relyea-Chew A, Hollingworth W, Chan L, et al. Personal bankruptcy after traumatic brain or spinal cord injury: the role of medical debt. Arch Phys Med Rehabil. 2009;90:413-419.

20. Meltzer $H$, Bebbington $P$, Brugha $T$, et al. Personal debt and suicidal ideation. Psychol Med. 2011;41:771-778.

21. Bickham T, Lim Y. in sickness and in debt: do mounting medical bills predict payday loan debt? Soc Work Health Care. 2015;54:518-531. 
22. Olfson $M$, Wang $S$, Wall $M$, et al. Trends in serious psychological distress and outpatient mental health care of US adults. JAMA Psychiatry. 2019;76: 152-161.

23. Chen J, Vargas-Bustamante A, Mortensen $\mathrm{K}$, et al. Racial and ethnic disparities in health care access and utilization under the Affordable Care Act. Med Care. 2016;54:140-146.

24. Novak P, Anderson AC, Chen J. Changes in health insurance coverage and barriers to health care access among individuals with serious psychological distress following the Affordable Care Act. Adm Policy Ment Health. 2018;45:924-932.

25. Jacobs A, Hill T, Burdette A. Health insurance status and symptoms of psychological distress among low-income urban women. Soc Ment Health. 2014;5:1-15.

26. Pearson WS, Dhingra SS, Strine TW, et al. Relationships between serious psychological distress and the use of health services in the United States: findings from the Behavioral Risk Factor Surveillance System. Int J Public Health. 2009;54 Suppl 1:23-29.

27. Adepoju O, Lin SH, Mileski M, et al. Mental health status and healthcare utilization among community dwelling older adults. J Ment Health. 2018; 27:511-519.

28. Lee DS, Marsh L, Garcia-Altieri MA, et al. Active mental illnesses adversely affect surgical outcomes. Am Surg. 2016;82:1238-1243.

29. Chen J, DuGoff EH, Novak P, et al. Variation of hospital-based adoption of care coordination services by community-level social determinants of health. Health Care Manage Rev. 2020;45:332-341.

30. Chen J. Evaluating the cost of mental illness: a call for a cost-effective care coordination model. Am J Geriatr Psychiatry. 2017;25:142-143.

31. Capp R, Misky GJ, Lindrooth RC, et al. Coordination program reduced acute care use and increased primary care visits among frequent emergency care users. Health Aff. 2017;36:1705-1711.

32. Anderson A, Chen J. ACO affiliated hospitals increase implementation of care coordination strategies. Med Care. 2019;57:300-304.

33. Cook BL, Zuvekas $\mathrm{SH}$, Chen J, et al. Assessing the individual, neighborhood, and policy predictors of disparities in mental health care. Med Care Res Rev. 2017;74:404-430.

34. Sherry M, Wolff JL, Ballreich J, et al. Bridging the silos of service delivery for high-need, high-cost individuals. Popul Health Manag. 2016;19: 421-428.

35. Horvitz-Lennon M, Kilbourne AM, et al. From silos to bridges: meeting the general health care needs of adults with severe mental illnesses. Health Aff. 2006;25:659-669.

36. Okumura $\mathrm{Y}$, Ito $\mathrm{H}$. Out-of-pocket expenditure burdens in patients with cardiovascular conditions and psychological distress: a nationwide cross-sectional study. Gen Hosp Psychiatry. 2013;35:233-238.

37. Colla $\mathrm{CH}$, Lewis VA, Kao LS, et al. Association between medicare accountable care organization implementation and spending among clinically vulnerable beneficiaries. JAMA Intern Med. 2016;176:1167-1175.

38. Yabroff KR, Zhao J, Han X, et al. Prevalence and correlates of medical financial hardship in the USA. J Gen Intern Med. 2019;34:1494-1502.
39. Cohen JW, Cohen SB, Banthin JS. The medical expenditure panel survey: a national information resource to support healthcare cost research and inform policy and practice. Med Care. 2009;47(7 Suppl 1):S44-S50.

40. Kessler RC, Andrews G, Colpe LJ, et al. Short screening scales to monitor population prevalences and trends in non-specific psychological distress. Psychol Med. 2002;32:959-976.

41. Kessler RC, Barker PR, Colpe LJ, et al. Screening for serious mental illness in the general population. Arch Gen Psychiatry. 2003;60:184-189.

42. Kessler RC. Epidemiology of women and depression. J Affect Disord. 2003; 74:5-13.

43. Prochaska JJ, Sung HY, Max W, et al. Validity study of the K6 scale as a measure of moderate mental distress based on mental health treatment need and utilization. Int J Methods Psychiatr Res. 2012;21:88-97.

44. Andersen RM. Revisiting the behavioral model and access to medical care: does it matter? J Health Soc Behav. 1995;36:1-10.

45. McKenna RM, Pintor JK, Ali MM. Insurance-based disparities in access, utilization, and financial strain for adults with psychological distress. Health Aff. 2019;38:826-834.

46. Kottke T, Abariotes A, Spoonheim JB. Access to affordable housing promotes health and well-being and reduces hospital visits. Perm J. 2018 22:17-079.

47. Hamilton $A B$, Cohen $A N$, Glover $D L$, et al. Implementation of evidencebased employment services in specialty mental health. Health Serv Res. 2013;48(6 Pt 2):2224-2244

48. James BD, Wilson RS, Shah RC, et al. Association of financial literacy with hospitalization in community-dwelling older adults. Med Care. 2018;56: 596-602

49. Federal Reserve Board. Report on the Economic Well-Being of U.S. Households in 2018 - May 2019. 2019. Available at https://www .federalreserve.gov/publications/2019-economic-well-being-of-ushouseholds-in-2018-dealing-with-unexpected-expenses.htm Accessed December 18, 2020.

Cite this article as: Novak PJ, Ali MM, Sanmartin MX (2020) Disparities in medical debt among U.S. adults with serious psychological distress, Health Equity 4:1, 549-555, DOI: 10.1089/heq.2020.0090.

$\begin{aligned} & \text { Abbreviations Used } \\ \mathrm{ACA}= & \text { Affordable Care Act } \\ \mathrm{Cl}= & =\text { confidence interval } \\ \mathrm{MEPS}= & \text { Medical Expenditure Panel Survey } \\ \mathrm{OR}= & \text { odds ratio } \\ \mathrm{SPD}= & \text { serious psychological distress } \\ \mathrm{FPL}= & =\text { Federal Poverty Level }\end{aligned}$

